\title{
EXTREMELY HIGH CURRENT, HIGH-BRIGHTNESS ENERGY RECOVERY LINAC*
}

\author{
I. Ben-Zvi", D. Barton, D. Beavis, M. Blaskiewicz, J. M. Brennan, A. Burrill, R. Calaga, P.
} Cameron, X. Chang, R. Connolly, D. M. Gassner, J. Grimes, H. Hahn, A. Hershcovitch, H.-C. Hseuh, P. Johnson, D. Kayran, J. Kewisch, R. Lambiase, V. N. Litvinenko, G. McIntyre, W. Meng, T. Nehring, A. Nicoletti, D. Pate, B. Oerter, J. Rank, T. Rao, T. Roser, T. Russo, J. Scaduto, Z. Segalov, K. Smith, N. Williams, K.-C. Wu, V. Yakimenko, K. Yip, A. Zaltsman, Y. Zhao (BNL, Upton, Long Island, New York), A. Burger, A. Favale, D. Holmes, M. Cole, J. Rathke, T. Schultheiss, H. Bluem, Alan Murray Melville Todd (AES, Medford, NY), J. R. Delayen, W. Funk, P. Kneisel, L. Phillips, J. P. Preble (Jefferson Lab, Newport News, Virginia)

\section{Abstract}

Next generation light-sources, electron coolers, highpower FELs, Compton X-ray sources and many other accelerators were made possible by the emerging technology of high-power, high-brightness electron beams. In order to get the anticipated performance level of ampere-class currents, many technological barriers are yet to be broken. BNL's Collider-Accelerator Department is pursuing some of these technologies for its electron cooling of RHIC application, as well as a possible future electron-hadron collider. We will describe work on $\mathrm{CW}$, high-current and high-brightness electron beams. This will include a description of a superconducting, laserphotocathode RF gun and an accelerator cavity capable of producing low emittance (about 1 micron rms normalized) one nano-Coulomb bunches at currents of the order of one ampere average.

\section{INTRODUCTION}

Extremely high current, high-brightness energy recovery linac is being built as part of the $\mathrm{R} \& \mathrm{D}$ towards electron cooling of RHIC [1]. Additionally, the reader may refer to the Zero Design Report on electron cooling of RHIC at our web site [2].

The electron cooling of RHIC requires an electron source with a very small emittance for the given $20 \mathrm{nC}$ charge as well as the use of magnetized (angular momentum dominated) electron beam. The repetition rate is as high as $9.4 \mathrm{MHz}$ and the energy is $54 \mathrm{MeV}$.

Clearly the development of such an electron beam involves significant $R \& D$ on a variety of subjects. This work is carried out by a number of collaborations with various institutes, as can be seen from the list of authors. It is impossible to cover this subject in one paper, however these proceedings include many other papers concerned with the various aspects of the science and technology of this ERL. We will refer the reader to details in these other papers for a more thorough deliberation.

$\left.{ }^{*}\right)$ Work performed under the auspices of the U.S. Department of Energy, and partially funded by the DOD Joint Technology Office and the Navy.

\#) ilan@bnl.gov

\section{AMPERE-CLASS ERL}

A high current Energy Recovery Linac (ERL) is under construction at BNL [3] This R\&D facility has goals to demonstrate $\mathrm{CW}$ operation of ERL with average beam current in the range of $0.1-1$ ampere, combined with very high efficiency of energy recovery. The possibility for future up-grade to a two-pass ERL is being considered. The heart of the facility is a 5 -cell $703.75 \mathrm{MHz}$ superconducting RF linac with HOM damping. Flexible lattice of ERL provides a test-bed for testing issues of transverse and longitudinal instabilities and diagnostics of intense $\mathrm{CW}$ e-beam. The layout of the ERL is shown in Figure 1.

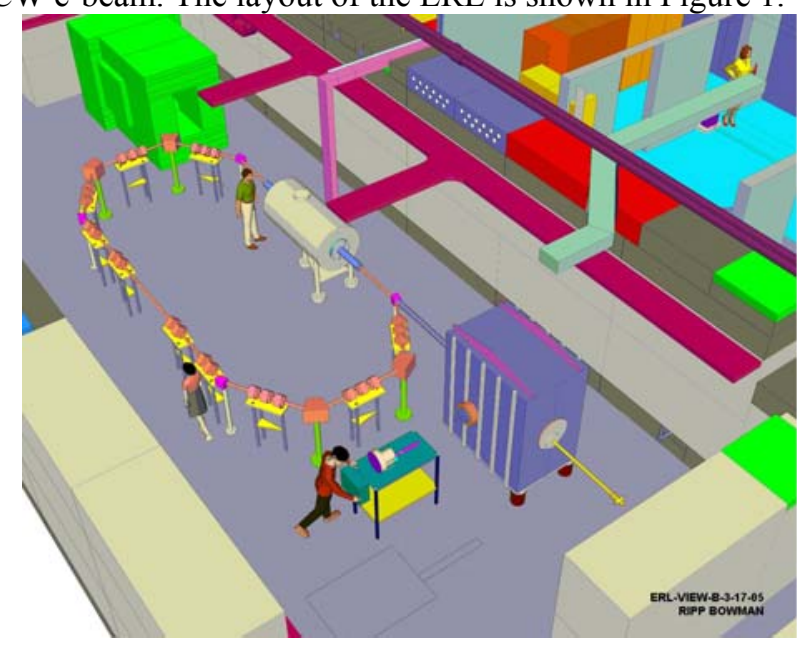

Figure 1: Layout of ERL. The gun is the square structure (blue) on the right, followed by the round 5-cell cavity cryomodule and the beam dump shielding.

Two operating modes are envisaged. In high current mode (1.4 nC at $350 \mathrm{MHz}, 1 \mathrm{~mm} \mathrm{mrad})$ the energy after the gun is $2 \mathrm{MeV}$, limited by the available RF power. In high charge mode (up to $10 \mathrm{nC}$ per bunch at $10 \mathrm{MHz}$ repetition rate, about $10 \mathrm{~mm}$ mrad normalized emittance) the super-conductive gun accelerates the beam to about 5 $\mathrm{MeV}$, limited by the maximum field in the gun.

The optical design of the machine and PARMELA [4] simulation from the cathode to the beam dump have been done. The design considerations and parameters obtained for different regimes of operation are presented by Kayran et. al. [5]. The Start-to-End simulation of the horizontal 
and vertical beam envelopes for $1.4 \mathrm{nC}$ bunch charge is show in Figure 2.

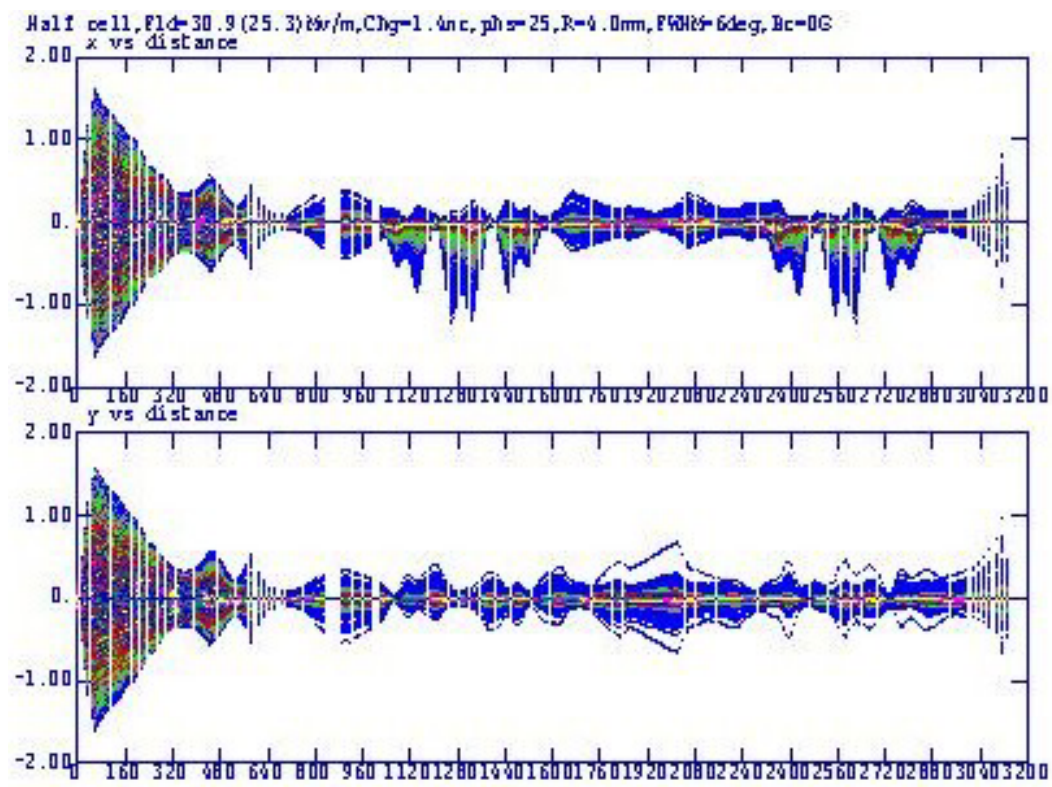

Figure 2: ERL Start-to-End simulation horizontal (upper figure) and vertical (lower ) beam envelopes, for a $1.4 \mathrm{nC}$.

\section{PHOTOCATHODE R\&D}

The high average current required from the gun calls for a photocathode with a large Quantum Efficiency (QE) (at least a few \%) in visible light, long life and benign behavior in the gun environment. We are developing cesium potassium antimonide photocathodes and their application in superconducting photoinjectors. Quantum efficiencies of $2-3 \%$ at $545 \mathrm{~nm}$, and $10 \%$ at $365 \mathrm{~nm}$ have been routinely obtained in the test stand, and electron emission uniformity, quantum efficiency at a variety of wavelengths, and lifetime under different vacuum conditions has been well characterized. R\&D now centers on the extraction of high charge per laser pulse [6].

The secondary emission enhanced photoinjector is a very promising new approach to the generation of highcurrent, high-brightness electron beams. In this scheme, primary electrons with a few thousand electron-volts of energy strike a specially prepared diamond window. The large Secondary Electron Yield (SEY) provides a multiplication of the number of electrons by about two orders of magnitude. The secondary electrons drift through the diamond under an electric field and emerge into the accelerating proper of the gun through a Negative Electron Affinity (NEA) surface of the diamond (which is hydrogen terminated). The primary electrons can be generated by a photocathode, and the large SEY serves as a multiplier of the quantum efficiency. Calculation of heating power sources and the detailed temperature distribution as well as some beam dynamics aspects are presented by Chang et. al. [7], showing feasibility of this kind of cathode.

In addition, experimental results demonstrate that indeed a large number of secondary electrons can be generated and transported across a diamond [8]. A few types of diamonds were experimentally checked for secondary emission. A single crystal CVD grown diamond yielded the highest electron and hole transmission. For this specific diamond a current gain of over 200 was measured for a $0.1 \mu \mathrm{A}$ primary electron beam through a 160 micron thick diamond window. An electric field in access of $10 \mathrm{MV} / \mathrm{m}$ was required to achieve the high current gain. It is evident from our measurements that the single crystal diamond had copious traps, some of them rather deep, thus preventing good transmission.

\section{THE ELECTRON GUN}

A key technology issue of ERL devices for our electron cooler, but also high-power free-electron laser (FEL) and 4th generation light sources, is the demonstration of reliable, high-brightness, high-power injector

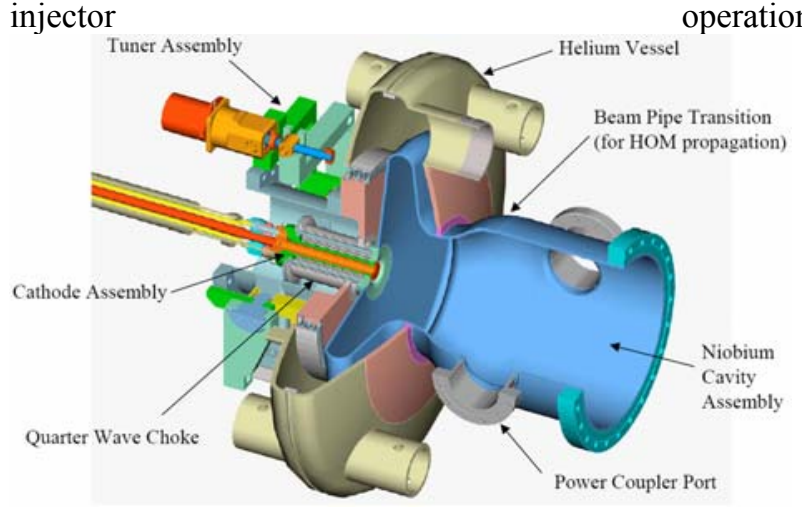

Figure 3: $703.75 \mathrm{MHz}$ superconducting photoinjector. 
Ongoing programs that target up to 1 Ampere injector performance at emittance values consistent with the requirements of these applications are in progress in various laboratories and at Advanced Energy Systems (AES) [9]. Three possible approaches that could deliver the required performance are pursued: a DC photocathode gun, a normal-conducting RF photoinjector and an SRF gun. We elected to develop a half-cell $703.75 \mathrm{MHz}$ SRF gun capable of delivering 1.0 Ampere. This device will be tested to 0.5 Ampere at our ERL.

The SRF gun cutaway diagram is shown in Fig. 3. it has a "half-cell" cavity and quarter-wave choke-joint for inserting a cathode assembly (from the left in the figure). To provide the necessary beam power, one sees ports for two fundamental power couplers rated at over $0.5 \mathrm{MW}$ each. The design of the beam-pipe allows for all HOMs to couple out to a beam-line ferrite HOM damper. The gun will provide $2 \mathrm{MeV}$ beam at 0.5 amperes with $1 \mathrm{MW}$ RF input power.

\section{THE SRF ERL CAVITY}

AES is currently under contract to BNL to fabricate the

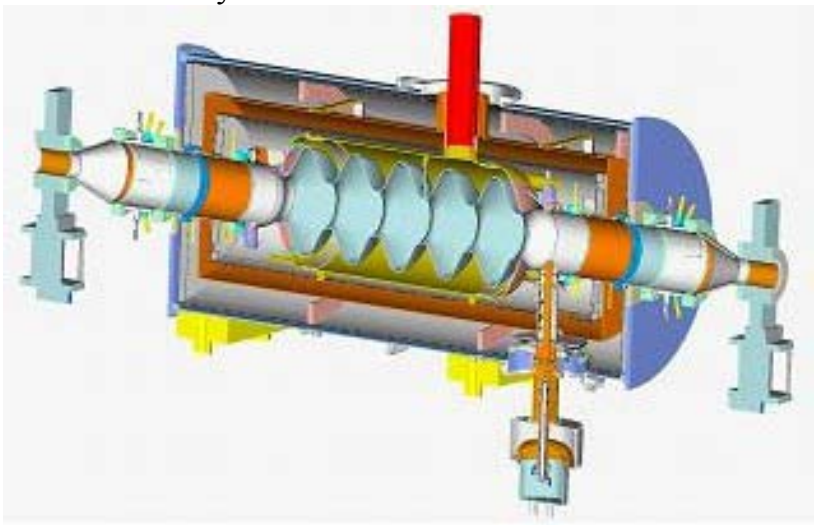

Figure 4: $703.75 \mathrm{MHz}$ 5-cell ERL cavity.

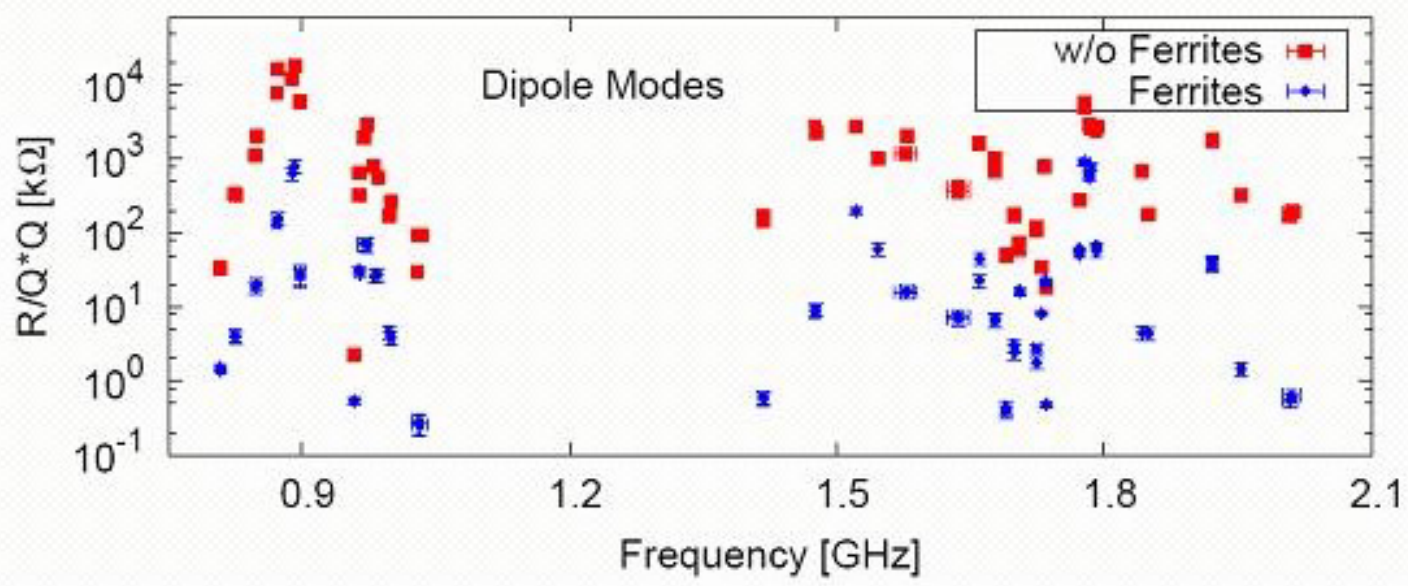

Figure 5: Dipole modes shunt impedance, bare copper cavity (Red) and the cavity with ferrites (blue).

five cell superconducting cavity and cryomodule for the ERL [10]. The cavity is designed and optimized for ampere class SRF ERL service. The HOM of the copper models were measured on two copper prototypes and the Qs of a large number of measured modes were compared with MAFIA simulations. The agreement was excellent [10] as can be seen from Fig. 5, where dipole modes are plotted. The $\mathrm{Q}$ values are quite low, thanks to the excellent damping by the ferrite HOM dampers, leading to a calculated beam breakup threshold of about 2 amperes in the $54 \mathrm{MeV}$ electron cooling ERL [11].

Some of the important parameters of the 5-cell cavity are as follows: Iris / beam pipe diameters $17 / 24 \mathrm{~cm}$. Geometry factor $225 \Omega, \mathrm{R} / \mathrm{Q}$ 403.5 $\Omega, \mathrm{Q}(\mathrm{BCS}, 2 \mathrm{~K})$ $4.5 \times 10^{10}, \mathrm{Q}_{\mathrm{ext}} 3 \times 10^{7} . \mathrm{E}_{\mathrm{p}} / \mathrm{E}_{\mathrm{a}} 1.97, \mathrm{H}_{\mathrm{p}} / \mathrm{E}_{\mathrm{a}} 5.78 \mathrm{mT} / \mathrm{MV} / \mathrm{m}$. Cell coupling $3 \%$, sensitivity factor 833 , field flatness 96.5\%, Lorentz detuning coeff. $1.2 \mathrm{~Hz} / \mathrm{MV} / \mathrm{m}$, lowest mechanical resonance $96 \mathrm{~Hz}$, loss factors at bunch rms length of $1 \mathrm{~cm} 1.1 \mathrm{~V} / \mathrm{pC}$ (longitudinal), $3.1 \mathrm{~V} / \mathrm{pC} / \mathrm{m}$ (transverse).

Copper prototypes were fabricated for the development of the tooling and RF measurements. The niobium cavity is being welded at this time.

\section{REFERENCES}

[1] I. Ben-Zvi, et. al, these proceedings, TPAp043

[2] http://www.agsrhichome.bnl.gov/eCool/

[3] V. Litvinenko, et. al, these proceedings, RPPT032

[4] Lloyd M. Young, James H. Billen. "PARMELA". Report LA-UR-96-1835, Los Alamos, 1996.

[5] D. Kayran, et. al, these proceedings, RPPT022

[6] A. Burrill, et. al, these proceedings, TPPE041

[7] X. Chang, et. al, these proceedings, TPPE042

[8] X. Chang, et. al, these proceedings, RPPE032

[9] A. Todd, et. al, these proceedings, WPAP033

[10] M. Cole, et. al, these proceedings, WPAT091

[11]R. Calaga et. al., proceedings of the ERL Workshop, Jefferson Lab. March 19-23, 2005.

This manuscript has been authored by Brookhaven Science Associates, LLC under Contract No. DE-AC0298CH10886 with the U.S. Department of Energy. The United States Government retains, and the publisher, by accepting the article for publication, acknowledges, a world-wide license to publish or reproduce the published form of this manuscript, or allow others to do so, for the United States Government purposes. 